\title{
Prognosis of Troponin-Positive Patients with Non- Obstructive Coronary Artery Disease
}

\author{
Nancy Z. K. Wassef · Javed Ehtisham • Neeta Petal • Naeem Shaukat
}

To view enhanced content go to www.cardiologytherapy-open.com

Received: January 23, 2014 / Published online: April 15, 2014

(C) The Author(s) 2014. This article is published with open access at Springerlink.com

\section{ABSTRACT}

Introduction: Troponin elevation is an independent risk factor for mortality, but the prognosis of patients with troponin elevation and non-obstructive coronary artery disease (CAD) is unknown. Recent data have suggested an increased risk of mortality. This study was performed to further investigate the outcomes of troponin-positive patients with obstructive and non-obstructive CAD.

Methods: A retrospective cohort analysis was performed of all patients with raised troponin presenting to Kettering General Hospital

Electronic supplementary material The online version of this article (doi:10.1007/s40119-014-0027-6) contains supplementary material, which is available to authorized users.

N. Z. K. Wassef $(\bowtie)$

Cardiology Department, New Cross Hospital,

Wolverhampton, UK

e-mail: nancy.wassef@gmail.com

J. Ehtisham · N. Shaukat

Cardiology Department, Kettering General Hospital,

Northamptonshire, UK

J. Ehtisham

e-mail: Javed.Ehtisham@kgh.nhs.uk

N. Petal

Internal Medicine Department, Leicester Royal

Infirmary, Leicester, UK
(January 2010 to December 2011, $n=1,351$ ). The patients who had angiograms were stratified anatomically into obstructive CAD and non-obstructive CAD ( $\leq 50 \%$ stenosis). The obstructive CAD group (O-CAD) was subanalyzed by management strategy: emergency re-vascularization $(<12 \mathrm{~h})$, urgent, delayed, and medically managed. Patients with nonobstructive CAD were grouped by the cause of the raised troponin if this could be identified (NO-CAD-I) or cause remained unidentified (NO-CAD-U). The major adverse cardiac and cerebrovascular event (MACCE) and mortality rates were calculated at 30 days and 1-year follow-up.

Results: There was a preponderance of hypertension and severe renal impairment in the non-obstructive CAD group. The patients with NO-CAD-U were a low-risk group (MACCE at 1 -year follow-up $=0$ ). The remaining NOCAD-I group had a similar risk to the O-CAD group for MACCE and mortality at 30 days and 1-year follow-up. In fact, at 1-year follow-up, the NO-CAD-I patients when compared with the subgroups of O-CAD, had higher MACCE rates and mortality compared with the emergency re-vascularized group [MACCE: 
relative risk $(\mathrm{RR})(95 \% \mathrm{CI})=2.27(1.29-3.40)$, $P=0.0047 ; \quad$ mortality: RR $(95 \% \quad$ CI $)=2.08$ (1.10-3.93), $P=0.024]$. This was driven by higher risk non-cardiac death [RR (95\% CI $=4.10$ (1.53-10.99), $P=0.005]$.

Conclusion: Patients with identified cause for raised troponin and non-obstructive $\mathrm{CAD}$ are at equivalent risk of MACCE and mortality at 30 days and 1-year follow-up compared to those with obstructive CAD.

Keywords: Coronary angiography; Coronary artery disease; Major adverse cardiac and cerebrovascular event; Mortality; Prognosis; Troponin

\section{INTRODUCTION}

Several studies have been performed evaluating the significance of a raised troponin in both ischemic heart disease and non-cardiac conditions [1]. While it has been found that cardiac troponins are valuable in the diagnosis of acute coronary syndromes (ACS), it has also been shown to be elevated in other cardiac (e.g., heart failure, myositis) and non-cardiac conditions (e.g., sepsis, renal failure, pulmonary embolism) [2, 3].

The prognosis of patients with nonobstructive coronary artery disease (CAD) is unknown, but recent small studies have found that patients with an elevated troponin level and non-obstructive CAD have an increased risk of death at 1-year follow-up, as well as death and recurrence of myocardial infarction at 2.5 years follow-up [4-6], especially noncardiac causes of death [5]. This study was performed to further investigate the outcomes of troponin-positive patients with obstructive and non-obstructive CAD.

\section{METHODS}

The analysis in this article does not involve any new studies of human or animal subjects performed by any of the authors. All procedures followed were in accordance with the ethical standards of the responsible committee on human experimentation (institutional and national) and with the Helsinki Declaration of 1975 , as revised in 2000 and 2008.

A retrospective cohort analysis that included all patients who had a raised cardiac troponin $T$ (cTnT; AQT90 FLEX [Radiometer Medical ApS, Brønshøj, Denmark], using the 99th percentile value of $0.017 \mathrm{ng} / \mathrm{ml}$ ) presenting to Kettering General Hospital (Northamptonshire, UK) between the period of January 2010 to December 2011 was performed. These patients were divided into two groups; the first group comprised patients who underwent coronary angiograms and the second group comprised patients who were too high risk for coronary angiograms and were medically managed. The patients who had angiograms were stratified anatomically, into non-obstructive epicardial CAD with $<50 \%$ stenosis (NO-CAD) and obstructive epicardial CAD with $\geq 50 \%$ stenosis (O-CAD). The NO-CAD patients were subgrouped by the cause of raised troponin if this could be identified (NO-CAD-I) versus the group where the cause remained unidentified (NOCAD-U). Also, the O-CAD cohort was analyzed by management strategy: emergent revascularization $(<12 \mathrm{~h}) ; \quad$ revascularization performed urgently as inpatient (mean of 2 days); delayed revascularization as outpatient; and medical management. The 30 days and 1-year major adverse cardiac and cerebrovascular events (MACCE) and the relative risk (RR) of death in the NO-CAD 
group were analyzed in comparison to O-CAD group. Furthermore, analyses of the NO-CAD subgroups were compared to the O-CAD subgroups. The Modification of Diet in Renal Disease equation (MDRD) equation was used to calculate the glomerular filtration rate for all patients [7].

\section{Statistical Methods}

The data were analyzed with the use of MedCalc version 12.7.2 (MedCalc Software bvba, Ostend, Belgium). The results were expressed as percentage or mean \pm standard deviation for categorical and continuous variables, respectively, due to normal population distribution. Significant differences between groups were assessed by $\chi^{2}$ test and Student's $t$ test in comparing between nominal and continuous variables, respectively. One-way analysis of variance test was used instead of Student's $t$ test in cases of more than two quantitative variables. Significance was ascribed with probability $<0.05$. The KaplanMeier survival curve was performed to compare the rate of mortality at 30 days and 1-year follow-up between the groups.

\section{RESULTS}

A total of 1,351 patients who presented to Kettering General Hospital with raised cTnT (from January 2010 to December 2011) were assessed included in the study. Of these, 962 patients (71.2\%) had coronary angiography, and 389 patients $(28.8 \%)$ were too high risk for angiography and were therefore medically managed. These patients had multiple comorbidities, which included severe renal impairment, peripheral vascular disease or critical illness requiring mechanical ventilation. Patients who had coronary angiography were stratified anatomically into those with O-CAD (847 patients, 62.6\%) and NO-CAD (115 patients, 8.5\%; Fig. 1).

The NO-CAD-I comprised 80 patients $(69.5 \%)$ and the NO-CAD-U comprised 35 patients (30.4\%). The O-CAD group comprised 374 patients who had emergency revascularization $(44.2 \%), 184$ patients who

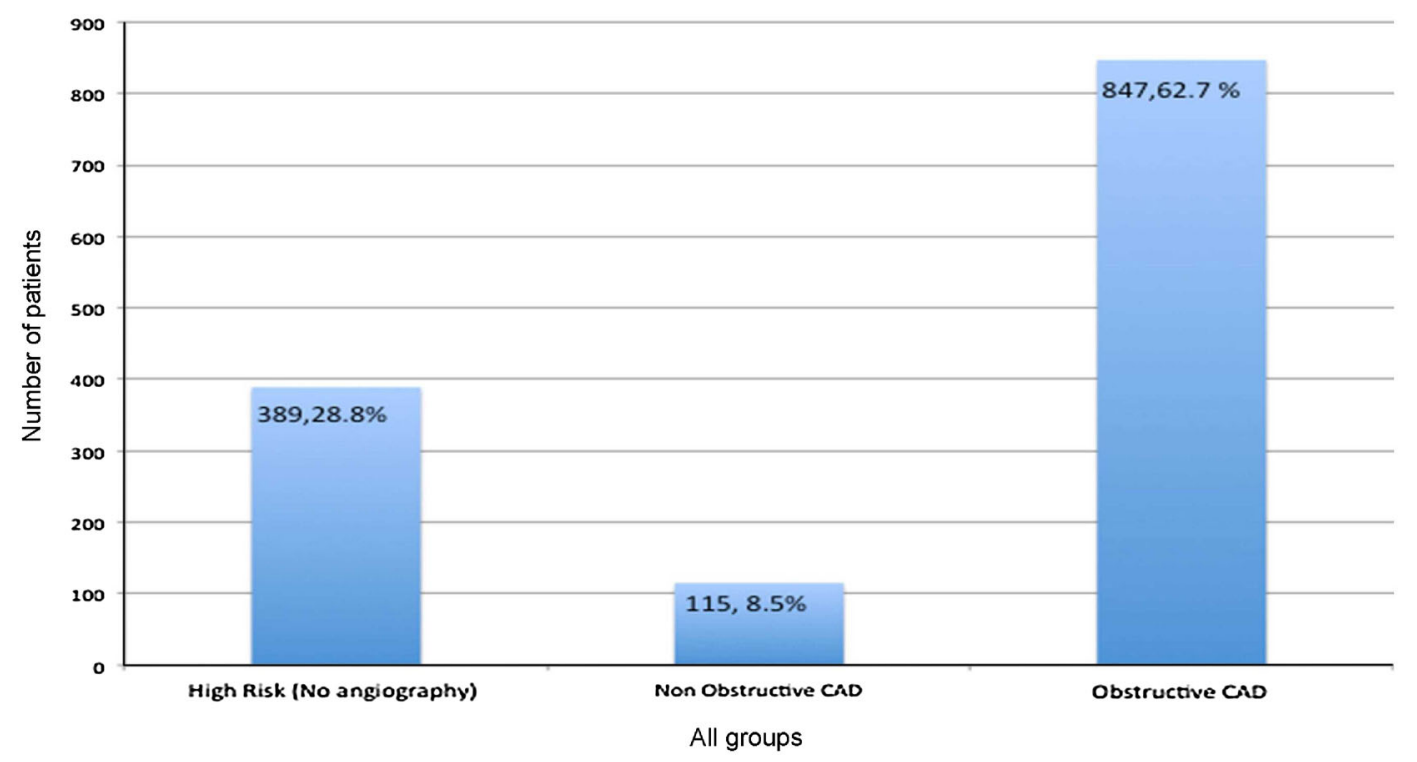

Fig. 1 Total number of patients. CAD, coronary artery disease 
Table 1 Demographics and risk factors for CAD

\begin{tabular}{llll}
\hline Demographics and risk factors for CAD & $\begin{array}{l}\text { Non-obstructive CAD group } \\
\boldsymbol{N = 1 1 5 ( 8 . 5 \% )}\end{array}$ & $\begin{array}{l}\text { Obstructive CAD group } \\
\boldsymbol{N = 8 4 7 ( 6 2 . 7 \% )}\end{array}$ & $\boldsymbol{P}$ value \\
\hline Age, years 4 SD & $67.3 \pm 14.1$ & $66.4 \pm 13$ & 0.981 \\
Gender & $56(48.7)$ & $610(72)$ & 0.541 \\
Male & $59(51.3)$ & $237(28)$ & \\
Female & $18(15)$ & $175(20)$ & 0.220 \\
Diabetes mellitus & $73(63)$ & $435(51)$ & 0.006 \\
Hypertension & $68(59)$ & $468(55)$ & 0.250 \\
Smoker & $17(14)$ & $102(12)$ & 0.397 \\
Ex-smoker & $8(7)$ & $77(9)$ & 0.454 \\
Dyslipidemia & $3(2)$ & $25(3)$ & 0.837 \\
Family history for CAD & & & \\
\hline
\end{tabular}

Values are given as $N(\%)$ unless otherwise stated

$C A D$ coronary artery disease, $S D$ standard deviation

had urgent revascularization as an inpatient (21.7\%), 114 patients who were discharged and returned for delayed outpatient revascularization (13.4\%), and 175 patients who were managed medically (20.6\%).

The mean age was equivalent between both groups and there were more female patients in the NO-CAD group when compared with the O-CAD. Comparing for risk factors for CAD showed that the NO-CAD group had a significant preponderance of hypertension (73 patients, $63 \%$ vs. 435 patients, $51 \%, P=0.0068$; Table 1).

The NO-CAD group had a trend toward lower level of cTnT elevation $(0.5 \pm 0.6$ vs. $2.4 \pm 4.7, P=0.121$ ) and a longer length of hospital stay $(9.1 \pm 16.4$ vs. $5.3 \pm 7.9$, $P=0.253)$. The evaluation of the renal functions showed that the NO-CAD group had more patients with severe renal impairment with a glomerular filtration rate $<15 \mathrm{ml} / \mathrm{min} /$ $1.73 \mathrm{~m}^{2}$ (5 patients, $4.3 \%$ vs. 5 patients, $0.5 \%$, $P=0.0014$; Table 2).
The comparison between the echocardiographic findings showed no structural heart disease by echocardiogram in the NO-CAD group (43 patients, $37 \%$ vs. 178 patients, $21 \%, P<0.0001)$ and more patients with aortic valve disease and left ventricular hypertrophy (Table 3).

The 30 days MACCE and mortality rates were similar between the NO-CAD and O-CAD groups [30 days MACCE: RR $(95 \% \mathrm{CI})=0.72$ (0.29-1.77), $\quad P=0.47 ; \quad 30$ days all-cause mortality: RR $(95 \% \quad \mathrm{CI})=1.24 \quad(0.54-2.86)$, $P=0.6124]$. At 1-year follow-up, the MACCE rate between the NO-CAD and the O-CAD groups was also equivalent [RR (95\% $\mathrm{CI})=1.21(0.75-1.96), P=0.43]$, with similar 1-year mortality in both groups [RR $(95 \%$ $\mathrm{CI})=0.93$ (0.53-1.64), $P=0.803$; Table 4].

The subgroup analysis of the NO-CAD group showed that the 35 patients who had no identifiable cause for the cTnT elevation were a low-risk group (MACCE at 1-year $=0$ ). In the NO-CAD group, the most common identified 
Table 2 Baseline anemia and renal impairment

\begin{tabular}{|c|c|c|c|}
\hline Blood investigations & $\begin{array}{l}\text { Non-obstructive CAD group } \\
N=115(8.5 \%)\end{array}$ & $\begin{array}{l}\text { Obstructive CAD group } \\
N=847(62.7 \%)\end{array}$ & $P$ value \\
\hline Hemoglobin, g/dl $( \pm S D)$ & $12.7 \pm 9.8$ & $13.4 \pm 3.4$ & 0.639 \\
\hline Creatinine, $\mu \mathrm{mol} / 1( \pm S D)$ & $112.4 \pm 94$ & $94.9 \pm 50$ & 0.332 \\
\hline \multicolumn{4}{|c|}{ GFR (rate $/ \mathrm{min} / 1.73 \mathrm{~m}^{2}$ ) and grade of renal impairment ${ }^{\mathrm{a}}$} \\
\hline GFR $>60$ & $76(66)$ & $640(75.5)$ & 0.054 \\
\hline IIIa 45-59.9 & $18(15.6)$ & $107(12.6)$ & 0.360 \\
\hline IIIb 30-44.9 & $8(6.9)$ & $72(8.5)$ & 0.576 \\
\hline IV $15-29.9$ & $8(6.9)$ & $24(2.8)$ & 0.023 \\
\hline $\mathrm{V}<15$ & $5(4.3)$ & $5(0.5)$ & 0.0014 \\
\hline
\end{tabular}

Values are given as $N(\%)$ unless otherwise stated

a Grades of renal impairment by MDRD equation

Table 3 Echocardiographic findings

\begin{tabular}{|c|c|c|c|}
\hline Echocardiographic findings & $\begin{array}{l}\text { Non-obstructive } \\
\text { CAD group } \\
N=115(8.5 \%)\end{array}$ & $\begin{array}{l}\text { Obstructive } \\
\text { CAD group } \\
N=847 \\
(62.7 \%)\end{array}$ & $P$ value \\
\hline Normal echocardiogram $^{a}$ & $43(37.4)$ & $178(21)$ & $<0.0001$ \\
\hline Severe/Moderate aortic valve disease & $8(6.9)$ & $13(1.5)$ & 0.0005 \\
\hline Moderate to severe $\mathrm{LVH}$ & $10(8.7)$ & $19(2.2)$ & 0.0003 \\
\hline Severe LV systolic impairment $(\mathrm{EF}<35 \%)$ & $10(8.7)$ & $61(7.2)$ & 0.2615 \\
\hline Moderate LV systolic impairment (EF 44-35\%) & $11(9.5)$ & $116(13.7)$ & 0.2306 \\
\hline Mild LV systolic impairment (EF 45-55\%) & $11(9.5)$ & $144(17)$ & 0.0525 \\
\hline Regional wall motion abnormality & $16(13.9)$ & $387(45.7)$ & $<0.0001$ \\
\hline Hypertrophic cardiomyopathy (Confirmed by CMR) & $1(0.8)$ & $0(0.0)$ & 0.0582 \\
\hline Takotsubo cardiomyopathy & $1(0.8)$ & $0(0.0)$ & 0.0582 \\
\hline Moderate to severe valvular heart disease & $2(1.7)$ & $35(4.1)$ & 0.2295 \\
\hline $\begin{array}{l}\text { Others (Right ventricular function impairment, Pulmonary hypertension, } \\
\text { ASD, VSD or Previous valve replacement) }\end{array}$ & $8(6.9)$ & $50(5.9)$ & 0.6551 \\
\hline No echocardiogram & $16(13.9)$ & $137(16.1)$ & 0.5383 \\
\hline
\end{tabular}

Values are given as $N(\%)$

a Normal echocardiography with no structural heart disease

causes were tachyarrhythmia (21\%), respiratory failure/severe pneumonia (6.9\%), sepsis (6\%), and advanced malignancies (6\%; Table 5).
When NO-CAD-I group was compared to the O-CAD group, they had similar 30 days MACCE and mortality rates [30 days MACCE: RR (95\% 
Table 430 days and 1-year MACCE and mortality follow-up

\begin{tabular}{|c|c|c|c|c|}
\hline Follow-up & $\begin{array}{l}\text { Non-obstructive } \\
\text { CAD group } \\
N=115(8.5 \%)\end{array}$ & $\begin{array}{l}\text { Obstructive } \\
\text { CAD group } \\
N=\mathbf{8 4 7}(\mathbf{6 2 . 7 \% )}\end{array}$ & Relative risk (95\% CI) & $P$ value \\
\hline \multicolumn{5}{|l|}{30 days follow-up } \\
\hline MACCE & $5(4.3)$ & $51(10.4)$ & $0.7221(0.29-1.77)$ & 0.4771 \\
\hline \multicolumn{5}{|l|}{ Death } \\
\hline Total & $6(5.2)$ & $39(4.6)$ & $1.24(0.54-2.86)$ & 0.6124 \\
\hline Cardiac & $4(3.4)$ & $30(3.5)$ & $0.98(0.35-2.74)$ & 0.9723 \\
\hline Non-cardiac & $2(1.7)$ & $9(1.0)$ & $1.63(0.36-7.48)$ & 0.5252 \\
\hline \multicolumn{5}{|l|}{ 1-year outcome } \\
\hline MACCE & $15(13.0)$ & $131(15.4)$ & $0.84(0.51-1.39)$ & 0.5021 \\
\hline Total & $12(10.4)$ & $95(11.2)$ & $0.93(0.53-1.64)$ & 0.8032 \\
\hline Cardiac & $5(4.3)$ & $48(5.6)$ & $0.77(0.31-1.89)$ & 0.5640 \\
\hline Non-cardiac & $7(6.0)$ & $43(5.0)$ & $1.2(0.55-2.60)$ & 0.6461 \\
\hline \multicolumn{5}{|l|}{ MI } \\
\hline STEMI & $2(1.7)$ & $24(2.8)$ & $0.61(0.12-2.56)$ & 0.5033 \\
\hline NSTE-ACS & $0(0.0)$ & $25(2.9)$ & $0.14(0.01-2.34)$ & 0.1727 \\
\hline Unplanned revascularization & $2(1.7)$ & $49(5.8)$ & $0.3(0.07-1.22)$ & 0.0925 \\
\hline CVA/TIA & $1(0.8)$ & $7(0.8)$ & $1.05(0.13-8.47)$ & 0.9619 \\
\hline Major bleeding $^{\mathrm{a}}$ & $3(2.6)$ & $24(2.8)$ & $0.92(0.28-3.01)$ & 0.8912 \\
\hline
\end{tabular}

CAD coronary artery disease, $C V A$ cerebrovascular stroke, $M A C C E$ major adverse cardiac and cerebrovascular events, $M I$ myocardial infarction, NSTE-ACS non-ST elevation ACS, STEMI ST elevation myocardial infarction, TIA transient ischemic attack

a Major bleeding that required blood transfusion

$\mathrm{CI})=1.03(0.42-2.52), P=0.934 ; 30$ days allcause mortality: RR $(95 \% \mathrm{CI})=1.68(0.71-3.73)$, $P=0.25]$. The 1-year MACCE and mortality follow-up rates were also similar [1-year MACCE: RR $\quad(95 \% \quad \mathrm{CI})=1.21 \quad(0.75-1.96)$, $P=0.43$; 1-year all-cause mortality: RR $(95 \%$ $\mathrm{CI})=1.34(0.77-2.33), P=0.31]$.

Further comparison of NO-CAD-I patients with the O-CAD subgroups showed no difference in 30 days MACCE and mortality rates. However, at 1-year follow-up, NO-CAD-I patients had higher MACCE rates and overall mortality compared to the emergency re- vascularization group [1-year MACCE: RR (95\% $\mathrm{CI})=2.27$ (1.29-3.40), $P=0.0047 ; 1$-year allcause mortality: RR $(95 \% \mathrm{CI})=2.08(1.10-3.93)$, $P=0.024]$. This increased mortality was driven by non-cardiac death $[\mathrm{RR}(95 \% \mathrm{CI})=4.10$ (1.53-10.99), $P=0.005$; Fig. 2).

\section{DISCUSSION}

Previous studies indicated that the detection of the highly specific troponin in blood is an independent risk factor that identifies patients presenting with unstable angina or non-ST 
Table 5 Causes of raised troponin in non-obstructive CAD group

\begin{tabular}{|c|c|c|}
\hline Identified cause & $N=115$ & $\%$ \\
\hline Tachyarrhythmia & 25 & 21.7 \\
\hline Respiratory failure/Severe pneumonia & 8 & 6.9 \\
\hline Sepsis & 7 & 6.0 \\
\hline Advanced malignancy & 7 & 6.0 \\
\hline Heart failure & 6 & 5.2 \\
\hline Myopericarditis & 5 & 4.34 \\
\hline Takotsubo syndrome & 4 & 3.47 \\
\hline Aortic valve disease & 4 & 3.47 \\
\hline Suspected vasospastic angina & 2 & 1.7 \\
\hline Pulmonary embolism & 2 & 1.7 \\
\hline Bradyarrhythmia & 2 & 1.7 \\
\hline Critically ill with ITU admission & 2 & 1.7 \\
\hline Cerebrovascular Stroke & 0 & 0.0 \\
\hline Acute kidney injury & 10 & 0.86 \\
\hline Aortic dissection & 1 & 0.86 \\
\hline Unknown & 35 & 30.4 \\
\hline IHD & 0 & 0.0 \\
\hline Post-PCI troponin rise & 0 & 0.0 \\
\hline
\end{tabular}

$C A D$ coronary artery disease, $I T U$ intensive care unit, $P C I$ percutaneous coronary intervention

elevation myocardial infarction, who are at increased risk of death [8, 9]. Troponin elevation can be seen in a variety of clinical scenarios, which may lead to its detection in the absence of thrombotic ACSs. Many disease states, such as sepsis, hypovolemia, atrial fibrillation, congestive heart failure, pulmonary embolism, myocarditis, myocardial contusion, renal failure, and critically ill patients can be associated with a raised troponin level (Table 6) [9-13].

In several studies of ACSs, troponin elevation has been associated with a worse prognosis [9, 14]. However, troponin elevation in the absence

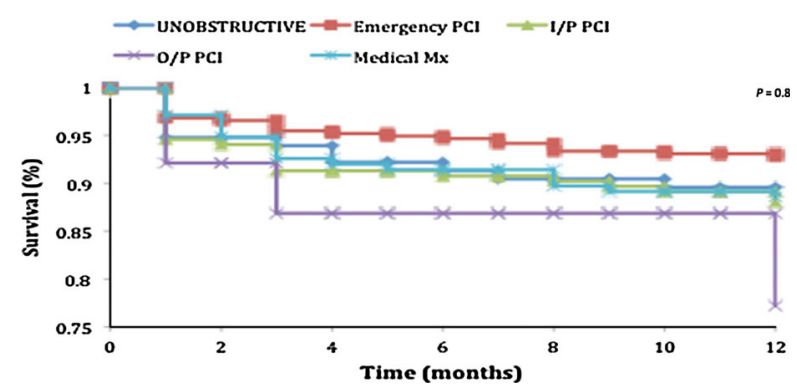

Fig. 2 Kaplan-Meier survival curve. $I / P$ PCI inpatient percutaneous coronary intervention, Medical $M x$ medical therapy, $O / P$ PCI outpatient percutaneous coronary intervention, $P C I$ percutaneous coronary intervention

of thrombotic ACS still retains the prognostic value [9]. The risk for subsequent death appears to be related to the degree of troponin elevation [8]. There is a significant increase in mortality with increasing levels of troponin, and the RR for death is 7.8 in patients with the high troponin levels compared to those with normal levels [8]. The short- and long-term survival rates are impaired among patients with troponin elevation in many different clinical settings, including congestive heart failure, sepsis, pulmonary disease, acute pulmonary embolism, and renal insufficiency [15]. The reasons for this increase in mortality are currently poorly understood, but may be related to myocardial necrosis with myocyte loss or underlying quiescent CAD [9].

These findings challenge the idea that these are "false-positive" troponin elevations and that these patients may be regarded as low risk for subsequent cardiovascular events [16]. Elevation of troponin in these patients may result from coronary atherothrombosis not evident using standard angiography or from other ischemic and non-ischemic mechanisms [16]. It was also previously shown that the incidental troponin rise was more common in older patients and was associated with a poorer prognosis compared to ACSs [17]. Given this substantially increased risk for adverse 
Table 6 Causes of raised troponin

- Chronic or acute renal dysfunction

- Severe congestive heart failure-acute and chronic

- Hypertensive crisis

- Tachy- or brady-arrhythmias

- Pulmonary embolism, severe pulmonary hypertension

- Inflammatory diseases, e.g., myocarditis

- Acute neurological disease, including stroke or subarachnoid hemorrhage

- Aortic dissection, aortic valve disease or hypertrophic cardiomyopathy

- Cardiac contusion, ablation, pacing, cardioversion, or endomyocardial biopsy

- Hypothyroidism

- Apical ballooning syndrome (Takotsubo cardiomyopathy)

- Infiltrative diseases, e.g., amyloidosis, hemochromatosis, sarcoidosis, scleroderma

- Drug toxicity, e.g., adriamycin, 5-fluorouracil, Herceptin, snake venoms

- Burns, if affecting $>30 \%$ of body surface area

- Rhabdomyolysis

- Critically ill patients, especially with respiratory failure, or sepsis

Information from: European Society of Cardiology (ESC) Guidelines for the management of ACS in patients presenting without persistent ST-segment elevation. The Task Force for the management of ACS in patients presenting without persistent ST-segment elevation of the ESC, 2011 [16]

outcomes, patients with troponin elevation in general require appropriate diagnostic evaluation and therapy aimed at the underlying disorder [9].

A previous study by Mehta et al. [4] compared patients who had elevated troponin levels and $<50 \%$ stenosis of any major coronary artery on angiography $(n=83)$ to patients with negative troponin levels. The patients with elevated troponin and non-obstructiveepicardial CAD had an increased incidence of death and recurrence of myocardial infarction at 2.5 years follow-up [4].

The current study compared patients with elevated cTnT with non-obstructive CAD versus obstructive epicardial CAD. The MACCE rate was similar at 30 days and 1-year follow-up. The mortality rate at 30 days follow-up for the nonobstructive CAD was $5.2 \%$ vs. $4.6 \%$ in the highrisk obstructive CAD group with a RR $(95 \% \mathrm{CI})$ of $1.24(0.54-2.86) \quad(P=0.61)$. The rate of mortality at 1 -year follow-up was $10.4 \%$ vs. $11.2 \%$ with a RR (95\% CI) of $0.93(0.53-1.64)$ $(P=0.8)$. This was similar to the results of the previous sub-study of the ACUITY trial, which showed that the patients with non-ST elevation ACS and elevated troponin but without obstructive CAD are still at considerable risk for 1-year mortality from cardiac and noncardiac causes [5]. This may be caused by unstable, ruptured plaques, but with no significant coronary lesions by angiography.

A small study by Ohlmann et al. [18] evaluated patients who had intravascular 
ultrasound showing ruptured plaques with no significant angiographic disease. They had a high death rate of $6 \%$ and a major adverse cardiac events (MACE) rate of $18 \%$ at a mean follow-up of 43 months [18].

This was also similar to the TACTICS-TIMI18 sub-study, which followed a total of 895 patients, from which 32 patients had positive troponin and non-obstructive CAD and they were compared to the three other groups for 6-month mortality, re-infarction, or readmission for ACS at 6-month follow-up. This sub-study demonstrated that those patients had an adverse prognosis with no significant difference in outcome between troponinpositive patients with CAD compared with those without CAD $(P=0.20) \quad[16,19]$. However, this was in contrary to the previous study by Segev et al. [17] which showed that the patients with non-obstructive CAD had a benign clinical outcome compared with those with normal coronary arteries during an intermediate term follow-up of 2.5 years with equal low MACE rate between the two groups. (1\% for both groups; $P=0.9$ ) [17].

Subgroup analysis has not previously been carried out. By sub-grouping the nonobstructive CAD group, we have shown that patients in the non-obstructive $\mathrm{CAD}$ group with no identified cause for the raised troponin were at low risk at 1-year follow-up (MACCE at 1-year $=0$ ). In the non-obstructive CAD group with identified cause, the most common causes of raised troponin were tachyarrhythmia, respiratory failure/severe pneumonia, sepsis and advanced malignancies (Table 6). This has been demonstrated in previous studies, with elevation Troponin in many different clinical settings, including congestive heart failure, sepsis, pulmonary disease, acute pulmonary embolism, and renal insufficiency [20-22]. The mechanism of troponin release is unknown in the absence of flow-limiting CAD, suggesting the presence of mechanisms other than thrombotic coronary artery occlusion, probably a transient loss in membrane integrity with subsequent troponin leakage or micro-vascular thrombotic injury [23].

Further comparison of this non-obstructive CAD group with identified cause to the obstructive CAD management subgroups demonstrated that these patients had higher 1-year MACCE rate and overall mortality compared with the emergency revascularized group. This increased mortality was driven by higher risk of non-cardiac death [RR (95\% CI) $=4.10$ (1.53-10.99), $P=0.005$; Fig. 2).

\section{CONCLUSION}

Patients with a raised troponin and nonobstructive CAD with an identified cause are at equivalent risk of MACCE and death at 30 days and 1-year follow-up compared to those with obstructive CAD. Patients in the non-obstructive CAD group were at a similar risk whether managed with urgent or delayed revascularization or medical therapy for obstructive CAD, with the best outcomes seen in the emergency revascularization group. This finding challenges the prevailing perception that these patients form a low-risk group.

\section{ACKNOWLEDGMENTS}

No funding or sponsorship was received for this study or publication of this article. All named authors meet the ICMJE criteria for authorship for this manuscript, take responsibility for the integrity of the work as a whole, and have given final approval for the version to be published. Contributed to this publication: Nancy Wassef 
and Neeta Petal for data collection, Nancy Wassef, Hany Wassef and Javed Ehtisham for data analysis, Nancy Wassef and Javed Ehtisham writing the manuscript, Naeem Shaukat gave the original idea and supervised the project.

Conflict of interest. Nancy Wassef, Javed Ehtisham, Neeta Petal, and Naeem Shaukat declare that they have no conflict of interest.

Compliance with Ethics guidelines. The analysis in this article does not involve any new studies of human or animal subjects performed by any of the authors. All procedures followed were in accordance with the ethical standards of the responsible committee on human experimentation (institutional and national) and with the Helsinki Declaration of 1975, as revised in 2000 and 2008.

Open Access. This article is distributed under the terms of the Creative Commons Attribution Noncommercial License which permits any noncommercial use, distribution, and reproduction in any medium, provided the original author(s) and the source are credited.

\section{REFERENCES}

1. Agewall S, Giannitsis E, Jernberg T, et al. Troponin elevation in coronary vs. non-coronary disease. Eur Heart J. 2011;32:404-11.

2. Esther AP, Bockel V, Tulleken JE, et al. Troponin in septic and critically ill patients. Chest. 2005;127:687-8.

3. Roongsritong C, Warraich I, Bradley C. Common causes of troponin elevations in the absence of acute myocardial infarction-incidence \& clinical significance. Chest. 2004;125:1877-84.

4. Mehta S, Morales PF, Pillai M, et al. Prognostic implications of elevated troponin in patients with suspected acute coronary syndrome with nonobstructive coronary artery disease. Circulation. 2007;116:624.

5. Planer D, Lincoff AM, Moses JW, et al. Prognosis of patients presenting with acute coronary syndromes with elevated serum troponins \& non-obstructive coronary artery disease: the ACUITY trial. JACC. 2011;58:387.

6. Antman EM, Tanasijevic MJ, Thompson B, et al. Cardiac-specific troponin I levels to predict the risk of mortality in patients with acute coronary syndromes. N Engl J Med. 1996;335:1342-9.

7. Florkowski CM, Chew-Harris JSC. Methods of estimating GFR-Different equations including CKD-EPI. Clin Biochem Rev. 2011;32:75-9.

8. Jeremias A, Gibson CM. Narrative review: alternative causes for elevated cardiac troponin levels when acute coronary syndromes are excluded. Ann Intern Med. 2005;142:786-91.

9. Heidenreich PA, Alloggiamento T, Melsop K, et al. The prognostic value of troponin in patients with non-ST elevation acute coronary syndromes: a metaanalysis. J Am Coll Cardiol. 2001;38:478-85.

10. Dokainish H, Pillai M, Murphy SA, et al. Prognostic implications of elevated troponin in patients with suspected acute coronary syndrome but no critical epicardial coronary disease, a TACTICS-TIMI-18 Sub-study. JACC. 2005;45:19-24.

11. Myint PK, Al-Jawad M, Chacko SM, et al. Prevalence, characteristics and outcomes of people aged 65 years and over with an incidental rise in cardiac troponin I. Cardiology. 2008;110:62-7.

12. Collinson PO. Sensitive troponin assays. Postgrad Med J. 2012;88:348-52.

13. Nikhilesh J, Sathyamurthy I. Troponins: current status in coronary artery disease. J Assoc Phys India. 2005;53:116-8.

14. Maeder M, Fehr T, Rickli H, et al. Sepsis-associated myocardial dysfunction: diagnostic and prognostic impact of cardiac troponins and natriuretic peptides. Chest. 2006;129:1349-66.

15. Skeik N, Patel DC. A review of troponins in ischemic heart disease and other conditions. Int J Angiol. 2007;16:53-8.

16. Hamm CW, Bassand J-P, Agewall S, et al. ESC Guidelines for the management of acute coronary syndromes in patients presenting without persistent ST-segment elevation. Eur Heart J. 2011;32:2999-3054. 
17. Segev A, Beigel R, Goitein O, et al. Non-obstructive coronary artery disease upon multi-detector computed tomography in patients presenting with acute chest pain-results of an intermediate term follow-up. Eur Heart J Cardiovasc Imaging. 2012;13:169-73.

18. Ohlmann P, Kim SW, Mintz GS, et al. Cardiovascular events in patients with coronary plaque rupture and non-significant stenosis. Am J Cardiol. 2005;96:1631-5.

19. Ammann P, Maggiorini M, Bertel O, et al. Troponin as a risk factor for mortality in critically ill patients without acute coronary syndromes. J Am Coll Cardiol. 2003;41:2004-9.

20. Al-Otaiby MA, Al-Amri HS, Al-Moghairi AM. The clinical significance of cardiac troponins in medical practice. J Saudi Heart Assoc. 2011;23:3-11.
21. DeFilippi C, Wasserman S, Rosanio S, et al. Cardiac troponin $\mathrm{T}$ and $\mathrm{C}$-reactive protein for predicting prognosis, coronary atherosclerosis, and cardiomyopathy in patients undergoing long-term hemodialysis. JAMA. 2003;290:353-9.

22. Alcalai R, Planer D, Culhaoglu A, et al. Acute coronary syndrome vs nonspecific troponin elevation. Arch Intern Med. 2007;167:276-81.

23. Patil H, Vaidya O, Bogart D. A review of causes and systemic approach to cardiac troponin elevation. Clin Cardiol. 2011;34:723-8. 